\title{
Afrontas queer/cu-ir: linguagem não-binária na escrita acadêmica (implicações políticas e possibilidades)
}

\author{
Ismar Inácio dos SANTOS FILHO (D) \\ Universidade Federal de Alagoas (UFAL)
}

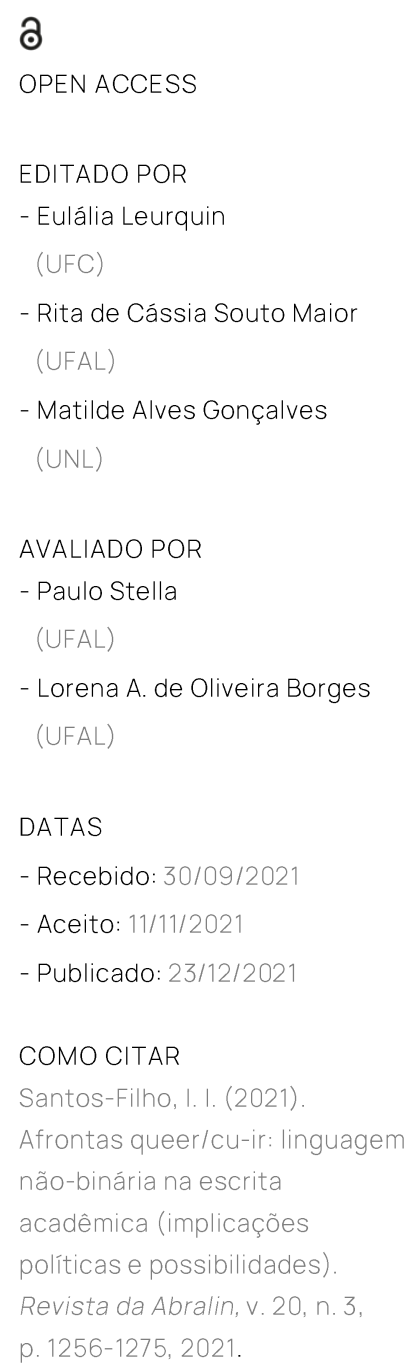

\section{RESUMO}

A discussão sobre linguagem (não) sexista e a respeito de ativismo linguístico não é nova. Se recuperarmos seu histórico, podemos ir ao século 18, quando Olympe de Gouges propôs a Declaração dos Direitos das Mulheres, com o argumento de que elas não se sentiam incluídas com a Declaração dos Direitos do Homem e do Cidadão, e também em contraposição à tradição gramatical francesa, conforme Borba (2020) e Lopes (2021). No Brasil, essa discussão é "recente", inicialmente no espaço da academia, no âmbito do feminismo. Todavia, nesses últimos anos, no ativismo transfeminista, a reivindicação por uma linguagem não-binária ganhou popularidade e chegou ao debate público, mobilizando inclusive o poder legislativo brasileiro, que vêm propondo decretos que visam proibir o uso do "gênero neutro" na esfera escolar e na administração pública. É nesse cenário de disputas linguístico-ideológicas que nos propomos a refletir acerca de possibilidades e implicações políticas do uso dessa linguagem na escrita acadêmica, numa maneira de afronta queer/cu-ir às normatividades/normalidades de língua e de corpos em nossa cultura. O estudo dialoga com Carvalho (2021), Bagno (2019), Borba (2020), Fabiano (2004; 2020), Lagares (2018; 2020), Moita Lopes (2013), Melo (2021) e Santos Filho (2015; 2020), dentre outras reflexões, e argumenta que usar a linguagem não-binária na escrita acadêmica é atuar para provocar urgentes desestabilizações de sentido, atuando na microfísica das tramas de forças do dizer científico, de modo a reconhecer todes. 


\section{REVISTA DA ABRALIN}

\section{ABSTRACT}

The discussion about (non)sexist language and about linguistic activism is not new. If we recover its history, we can go back to the 18th century, when Olympe de Gouges proposed the Declaration of the Rights of Women, arguing that they did not feel included with the Declaration of the Rights of Man and of the Citizen, and also in opposition to tradition French grammar, according to Borba (2020) and Lopes (2021). In Brazil, this discussion is recent, initially in the academic space, in the scope of feminism. However, in recent years, in transfeminist activism, the demand for a non-binary language has gained popularity and reached the public debate, even mobilizing the Brazilian legislature, which has been proposing decrees that aim to prohibit the use of "grammatically-neutral gender" in the school sphere and in public administration. It is in this scenario of linguistic-ideological disputes that we propose to reflect on the possibilities and political implications of the use of this language in academic writing, in a queer/cu-ir way of confronting the normativities/normalities of language and bodies in our culture. The study dialogues with Carvalho (2021), Bagno (2019), Borba (2020), Fabiano (2004; 2020), Lagares (2018; 2020), Moita Lopes (2013), Melo (2021) and Santos Filho (2015; 2020), among other reflections, and argues that to use non-binary language in academic writing is to act to provoke urgent destabilization of meaning, acting in the microphysics of the webs of forces of scientific speech, in order to recognize "todes".

\section{PALAVRAS-CHAVE}

Escrita acadêmica. Gênero gramatical. Linguagem não-binária.

\section{KEYWORDS}

Academic writing. Grammatical gender. Non-binary language.

\section{Introdução}

É importante informar que a discussão aqui realizada ocorreu inicialmente dentro da disciplina "Pesquisa Orientada", ministrada pela professora doutora Ana Flávia Ferraz, no curso de Teatro, na UFALCampus A.C. Simões, de quem recebi o convite para proferir uma fala, em 20 de abril de 2021, como palestra, que recebeu o mesmo título deste texto, no evento "Diálogos em Pesquisa Orientada", promovido pelo "Núcleo de Estudos e Pesquisa das Expressões Dramáticas" (NEPED), coordenado pelo 


\section{REVISTA DA ABRALIN}

professor doutor Otávio Cabral. A reflexão teve como objetivos gerais refletir e problematizar sobre o uso da "linguagem não-binária" na escrita acadêmica, especificamente no Trabalho de Conclusão de Curso (TCC), seja monografia, seja artigo. Na esteira dos estudos sobre escrita acadêmica, a abordagem efetivada neste texto mantém os objetivos antes referidos, mas não se restringe aos gêneros acadêmicos citados, pois abarca também outros textos da esfera acadêmica, tais como capítulos de livro e livros, por exemplo.

Nessa reflexão, preliminarmente, fez/faz-se necessária uma argumentação acerca do que entendemos sobre escrita acadêmica, especificamente a respeito de escrita de trabalho de conclusão de curso, o que nos exige apresentar uma noção sobre pesquisa, uma conceituação sobre produção de conhecimento, tentando nos filiarmos a um paradigma de produção de saber científico, e, a partir desse, pensarmos essa escrita e sua função social. Nesse sentido, discutimos acerca do que denominamos de "fazer científico" e "escrita acadêmica" e apresentamos implicações políticas e possibilidades de usos de uma "linguagem não-binária" nessa esfera de comunicação, noção que, do mesmo modo, pede-nos uma conceituação, adentrando, portanto, no âmbito do que pode ser denominado de letramento acadêmico, nos termos de Bazerman (2006) e Fabiano (2004; 2020).

Feitas tais considerações, de modo geral, mas de maneira breve, podemos já dizer, a partir de Borba (2020), Borba e Medeiros (2021), Borba e Lopes (2018), Lagares (2018; 2020), Lau (2019a; 2019b), Santos Filho (2015; 2017) e Silva (2018) que a "linguagem não-binária" diz respeito aos (usos de) recursos linguísticos que intentam uma marcação linguística não-binária de gênero (social), ao subverter a binariedade de gênero (masculino e feminino), podendo inclusive subverter os recursos (clássicos) morfológicos de gênero, para alcançar tal efeito. Mais adiante, discutimos acerca de alguns desdobramentos dessa noção.

Entretanto, acerca dessa conceituação, dada a nossa cultura de normatividades sobre a língua e sobre os corpos/sujeitos, que é uma cultura de "sistemas de reconhecimento" pautados em "normalidades" (língua padrão/culta, patriarcado, regimes da sexopolítica e de gênero - heteronormatividade e cisnormatividade), é relevante compreendermos que pensar sobre a linguagem não-binária na escrita acadêmica nos termos apresentados, ou em práticas discursivas de modo geral, ou usar essa "neo-linguagem", são ações que se constituem como uma "afronta", isto é, se dão como "enfrentamentos", "confrontos" e "ataques", ou melhor, como atos subversivos.

Nessa cultura, tais usos e tais ações, mencionados anteriormente, se configuram como uma "afronta" por que nossa "cultura letrada" se pauta essencialmente pela denominada "norma padrão" - de viés gramatical normativo, que é prescritivo - ou pela denominada "norma culta" - de caráter linguístico-descritivo. Assim, quando pensamos em língua, temos hegemonicamente noções que estão pautadas na normalidade, noções marcadas por um "ideal linguístico", o que implica em um caráter conversador, fundado em hierarquias sociais. Dessa maneira, tais normas estão para a "língua do patrão" (BAGNO, 2019), do homem, branco, cis, heterossexual, cristão, economicamente favorecido, conforme argumentam Melo (2021), que cita estudos sociolinguísticos, a exemplo dos de 


\section{REVISTA DA ABRALIN}

Marcos Bagno, e Carvalho (2021). No Brasil de hoje, o "patrão" está também, numa quimera discursiva, para o homem de extrema direita, ou um "bolsoopressor"1, para o denominado "cidadão de bem".

Na mesma direção, quando pensamos sobre os sujeitos, são os corpos em binariedade (homemmulher, macho-fêmea, masculino-feminino) que guiam o olhar em nossa cultura, percebidos como identidades primárias em oposição, entendidos como frutos de uma (suposta) coerência interna entre "sexo", "gênero" e "desejo", pautando-se na ideia de um corpo cisgênero/heterossexual, em uma perspectiva de "identidade" como essência. Essa noção, no entanto, nega a pluralidade e a dinamicidade das vivências de gênero e sexualidade. Assim, as normas linguísticas servem às normas sociais, pois lhes sustentam. Desse contexto sociocultural, político-ideológico, usar e ou refletir sobre lin-

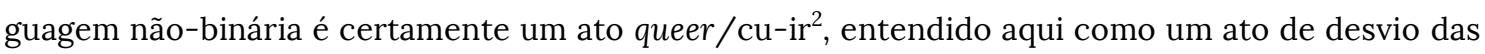
normalidades, portanto, de subversão a essas, e também de alianças entre corpos/sujeitos marginalizados, aqueles corpos/sujeitos colocados em condição de inviáveis, matáveis, tais como os corpos que não se reconhecem na binariedade de gênero.

Nessa compreensão, tomamos nossa reflexão como uma afronta queer/cu-ir, discussão que se fundamenta em estudos queer/cu-ir, de teóricos, teóricas e teoriques ${ }^{3}$ queer e de linguistas queer, considerações de caráter indisciplinar que entendem a língua(gem) em sua dimensão político-ideológica e que, por isso, estabelecem diálogos com estudos de caráter pós-estruturalistas e decoloniais, lutando contra a unicidade, a normalidade. É importante mencionar que essa discussão, com essa temática, nasceu a partir de uma demanda, qual seja, a necessidade/vontade uma pessoa, alune no curso de Teatro (UFAL-Campus A. C. Simões), que, ao se reconhecer como não-binárie, intenta escrever seu trabalho de conclusão de curso (TCC) se utilizando de recursos da linguagem nãobinária, de modo a se marcar nessa escrita e a marcar/reconhecer em seu texto acadêmico a existência de pessoas não-binárias, de maneira a ampliar a noção de gênero social, fazendo, assim, pensar gênero em um espectro, em um contínuo, corroendo o binarismo genérico na vida social e na linguagem. Essa discussão e essa demanda estão no universo do que podemos denominar de "linguagem inclusiva" e, portanto, no "ativismo linguístico".

\footnotetext{
${ }^{1}$ Ao mencionar a nomeação "bolsoopressor" estou me referindo a uma reportagem de Jáder Santana, no jornal "O Povo", em fevereiro de 2019, intitulada "Bolsolteiro por uma semana", na qual é apresentada uma narrativa sobre comportamentos de homens solteiros e mulheres solteiras, de explícito apoio ao atual presidente da República, Jair Bolsonaro, em um grupo fechado de mensagens virtuais ao qual o jornalista teve acesso por uma semana. Segundo informa, nesse grupo, uma nomeação a esses homens se dá pela palavravalise "bolsoopressores", que são "bolsolindos", "bolsolteiros", palavras nas quais, a redução "bolso_", de "Bolsonaro", se conecta a adjetivos, por exemplo, na constituição desses amálgamas lexicais, que indexam gênero e sexualidade imbricados a um pensamento político de direita, ou de extrema direita. É o "cidadão de bem", marcado morfologicamente sempre no masculino.

${ }^{2}$ Ao usar o termo "cu-ir", em referenciação ao "queer", estou me filiando à compreensão de Lewis et. al. (2017), em diálogos com Pelúcio (2016), de que se faz necessário romper com o discurso colonial anglo-americano e, dessa maneira, tensionar as nossas produções epistemológicas quando discutimos a respeito de linguagem e corpos e subversões sócio-políticas.

${ }^{3}$ É importante esclarecer que ao longo deste texto aparecerão palavras (nomes e artigos), como "teoriques", que estão marcadas morfologicamente por estratégias linguísticas de caráter não-binário.
} 


\section{REVISTA DA ABRALIN}

Em resumo, esta discussão $a$ ) versa sobre escrita acadêmica, momento no texto em que apresento exemplos de usos de recursos linguísticos, em livros, que enfrentam o "masculino genérico" e a binariedade linguística de gênero, $b$ ) discute a respeito do "fazer ciência", argumentando em defesa de um conhecimento e uma escrita "interessados", e, por fim, c) reflete e problematiza acerca da noção de linguagem não-binária e seus usos na esfera acadêmica, trazendo explicações técnicas, linguístico-formais, de modo a apresentar recursos e estratégias linguísticas no enfrentamento da binariedade linguístico-social de gênero.

\section{Por uma noção inicial de escrita acadêmica, linguagem inclusiva; linguagem não-binária}

O que se espera da escrita acadêmica, na escrita de um trabalho de conclusão de curso, por exemplo? Para falar de modo situado, de acordo com a Resolução de TCC (01/2018), versão da Resolução/2013, do curso de Letras (UFAL-Campus do Sertão), o trabalho de conclusão de curso é uma "monografia", entendida enquanto um texto escrito, resultado de uma pesquisa acadêmica. Ao se referir a esse texto como fruto de uma pesquisa acadêmica, a Resolução mencionada diz que esse estudo se pauta por um "problema de pesquisa", que está para uma "temática", necessitando estar situado em uma área de conhecimento e filiado a um paradigma epistemológico, que instituem uma "abordagem metodológica”, de geração e de análise de dados. Na prática, a orientação está para leituras e diálogos com outras pesquisas, com outros textos, que abordam aquela temática e o objeto ali constituído, de modo a construir um olhar para o objeto estudado, de maneira a tratar esse objeto e de forma a analisá-lo e a interpretá-lo. Nessa compreensão, e a grosso modo, a escrita de pesquisa é um "dizer" sobre o objeto estudado, uma interface entre o objeto empírico e o que sobre ele já nos foi (academicamente) dito.

Assim, espera-se que essa escrita, esse "dizer", se expresse através do que podemos denominar de "letramento acadêmico", isto é, que se paute em a) leitura crítica e autônoma na (re)construção de saberes e na b) operacionalização do discurso acadêmico em seus aspectos linguístico-discursivos. Nesse sentido, o dizer acadêmico não é, e não pode ser, neutro, pois a leitura crítica e a escrita crítica estão para um posicionamento crítico/político, enquanto possibilidade de assumir certa "autoria". Na escrita acadêmica, a autoria está para a produção de certos "deslocamentos de sentido", conforme Fabiano (2004), seja nos recortes realizados na/para a pesquisa, seja na "arte de dialogar com a palavra do outro" (FABIANO, 2020), de modo a “(...) se colocar de maneira a não funcionar como mero reprodutor da fala alheia" (FABIANO, 2004, p. 130-131). Nessa escrita, portanto, não basta apenas adequação às estruturas linguísticas e às normas técnicas, pois só esses aspectos pouco contribuem para que a produção não se constitua de meras réplicas, cópias ou colas.

Frente a esse caráter da escrita acadêmica, compreendemos que através de determinadas estratégias e recursos linguístico-discursivos, o sujeito que escreve pode se inserir na enunciação, 


\section{REVISTA DA ABRALIN}

enquanto ato de posicionamento, marcando-se como enunciador e, assim, provocar determinados "deslocamentos de sentido". Logo, o sujeito que escreve não só repete, mas, preferencialmente, reafirma determinados sentidos, aproxima-se deles, problematiza-os, distancia-se e até convoca outros sentidos. Nessa direção, e apenas para exemplificar, a recusa de uso dos pronomes demonstrativos "isto" e "isso" na função de referenciar, no processo de progressão textual, no processo de retomada, é um modo de posicionamento, é um modo de autoria, no dizer acadêmico, já que, nessa compreensão, "isto" ou "isso" se constituem como "pronomes vazios de posicionamento ${ }^{4}$ ", pois são usos que impedem que o sujeito que escreve, na referenciação, se insira na enunciação e, além disso, tais usos prejudicam a informatividade. Nessa argumentação, esse mecanismo de progressão textual, por um "pronome vazio", se constitui em um caso problemático de progressão. Na discussão, então, um exemplo desse caso nos é dado, a partir de um recorte de escrita dentro do Grupo de Estudos em Linguística Aplicada em Questões/Queer do Sertão Alagoano (GELASAL):

\section{Excerto 01}

[Pautando-se nas ideias de Albuquerque Jr. (2019)] Na segunda metade do século XIX, emergiu a então chamada "literatura das secas" do Norte, textos literários com uma estrutura narrativa singular, a partir do fenômeno da estiagem, denominada de "seca", estrutura narrativa centrada no acontecimento da retirada. A literatura das secas veio, inicialmente, responder a um projeto político e literário e, por que não dizer, discursivo, que intentava criar uma literatura do Norte, conforme aparece no proposto prefácio da obra "O Cabeleira", do escritor cearense Franklin Távora, obra publicada em 1876.

Com ISSO, o escritor Franklin Távora estabelece algumas imagens e figuras que seriam tomadas como icônicas desse lugar e que deveriam se fazer presentes em textos subsequentes que pretendessem ocupar este espaço.

$\mathrm{Na}$ argumentação acerca da necessidade de deslocamentos de sentido na escrita acadêmica, ao se usar o pronome "isso" na retomada, como ocorreu no excerto 01, acima mostrado, o sujeito que escreve perde uma possibilidade de posicionamento, diferentemente se, no lugar da palavra "isso", fizesse uso de uma expressão nominal como "essa proposta literário-discursiva", como inserida na orientação apresentada abaixo, que funcionaria como expressão de compreensão e de posição acerca do que está apresentando a partir das ideias do historiador e do literato citados. Essa "simples" estratégia de troca do pronome "isso" por uma "expressão nominal" no processo de retomada na progressão textual geraria condição de autoria. Como proposta de substituição do pronome "isso", que aparece no Excerto 01, é apresentada a seguinte redação, conforme já apontamos:

\footnotetext{
${ }^{4}$ Aula intitulada "Um caso problemático de progressão textual em texto acadêmico (?): a retomada por um 'pronome vazio"', no curso "TCC em perspectivas", no curso de Letras (UFAL-Campus do Sertão), em 18 de novembro de 2020, proferida por mim.
} 


\section{REVISTA DA ABRALIN}

Com ESSA PROPOSTA LITERÁRIO-DISCURSIVA, o escritor Franklin Távora estabelece algumas imagens e figuras que seriam tomadas como icônicas desse lugar e que deveriam se fazer presentes em textos subsequentes que pretendessem ocupar este espaço.

Nessa direção de pensamento, o que argumentar a respeito das escolhas linguístico-discursivas destacadas nos recortes de textos acadêmicos que seguem, no tocante às questões de gênero?

\section{Excerto 02}

Também nas referências bibliográficas, é evidente a presença maciça de linguistas brasileirxs ou que trabalham no Brasil, com muitxs dxs quais dialogo aqui por escrito (...). Também minhas aulas na pósgraduação e o diálogo com estudantes e orientandxs me permitiram organizar ideias, descobrir possíveis inconsistências e perceber questões que antes não tinha contemplado. Por isso, gostaria de expressar aqui a elas e a eles o meu agradecimento. (LAGARES, 2018, p. 11-12).

\section{Excerto 03}

Este trabalho traz uma reflexão acerca de uma nova forma de linguagem aplicada na língua portuguesa em que, ao contrário das práticas empregadas no discurso, referidas aos sujeitos, uma forma que não marque exclusivamente um gênero binário. Ao comentar sobre essa linguagem, advinda de pessoas que não se auto identificam com o binário de gênero, os pronomes da língua portuguesa podem não representar elus. Ao comentar sobre ela, faço uso dessa marca de linguagem durante a redação deste trabalho ao analisar os discursos advindos de uma propaganda da Avon em 2016 e de uma conversa com pessoas não-binárias. (LAU, 2019b, p. 186).

No Excerto 02, Lagares (2018), na “Apresentação" do livro "Qual política linguística? Desafios glotopolíticos contemporâneos", publicado pela Parábola Editorial, faz a escolha linguístico-discursiva de usar a) o "-x" como marcador de gênero, de modo a fugir do binarismo de gênero marcado pelos morfemas gramaticais de gênero "-o" e “-a”, em língua portuguesa, em palavras como "brasileirxs", "orientandxs", "muitxs", "dxs", nomes, quantificador e preposição em contração, e b) a expressão "a elas e a eles", para não fazer uso do "masculino genérico", "eles" apenas. Já Lau (2019b), no Excerto 03, no texto "Propaganda inclusiva e uma conversa sobre representatividade em língua portuguesa: notas sobre a linguagem não-binária", capítulo publicado no livro "Pesquisar em tempos de resistência - a balbúrdia de quem faz Linguística Aplicada", organizado por Hélito Diego Lau e Zuleica Aparecida Michalkiewicz, pela editora Pimenta Cultural, faz uso da palavra "elus", para não marcar nem "eles", pronome pessoal, na terceira pessoa plural, no "masculino genérico", nem "elas e eles", expressão que também recusa a marcação da terceira pessoa plural no "masculino genérico", mas que fica ainda na binariedade de gênero. Logo, o uso de "elus" é um recurso linguístico usado justamente para fazer marcação de não-bináries, mas que pode também ser usado como marcação de "gênero neutro". Mais à frente fazemos um aprofundamento dessa questão. 


\section{REVISTA DA ABRALIN}

Podemos afirmar que, por essas escolhas linguístico-discursivas, essa "escrita [acadêmica] é imbuída de agência", conforme Bazerman (2006, p. 11), que compreende que a escrita envolver agência significa a) participação competente nas sociedades letradas complexas, por b) realizar coisas no mundo em mudança através da escrita, c) criar e $d$ ) estar em riscos. Nos recortes de escrita acadêmica antes mencionados, a escrita está sim imbuída de agencia, pois está para uma atividade de afronta a "Um mundo conservador [mas] que se abala com a mais leve pluma de crítica", como afirma Tiburi (2018, p. 11). No que se refere às marcações linguísticas de gênero, essa pesquisadora argumenta que "Para identificar o gênero não binário [em seu livro], em lugar de 'x' ou '@', optamos por usar a letra 'e' (como em 'todes') - de modo a não criar barreiras para a acessibilidade do conteúdo por deficientes visuais" [inserção nossa] (TIBURI, 2018, p. 11). Além desse aspecto, ela considera que,

\footnotetext{
O feminismo nos leva à luta por direitos de todas, todes e todos. Todas porque quem leva essa luta adiante são as mulheres. Todes porque o feminismo liberou as pessoas de se identificarem somente como mulheres ou homens e abriu espaço para outras expressões de gênero - e de sexualidade - e isso veio interferir no todo da vida. Todos porque luta por certa ideia de humanidade (que não é um humanismo, pois o humanismo também pode ser um operador ideológico que privilegia o homem em detrimento das mulheres, dos outros gêneros e, até mesmo, das outras espécies), e, por isso mesmo, considera que aquelas pessoas definidas como homens também devem ser incluídas em um processo realmente democrático, coisa que o mundo machista - que conferiu aos homens privilégios, mas os abandonou a uma profunda miséria espiritual - nunca pretendeu realmente levar à realização [negrito nosso] (TIBURI, 2018, p. 11-12).
}

Dada essa compreensão e a partir desse posicionamento na escrita acadêmica, o título do livro mencionado de Márcia Tiburi é "Feminismo em comum para todas, todes e todos", publicado pela editora "Rosa dos Tempos", e o último capítulo está intitulado "Pensar juntas, juntes e juntos: por um feminismo comum". Desses exemplos de escrita acadêmica, de Xoán Lagares, Hélito Lau e Márcia Tiburi, podemos perceber algumas escolhas na construção de uma "linguagem inclusiva", quais sejam, a) ora o afastamento do masculino genérico, b) ora a marcação não-binária de gênero, a partir de estratégias bem peculiares, como é possível perceber. Dessa maneira, tais usos afrontam/enfrentam as normas linguísticas (padrão e culta) de gênero, aquelas que, conforme já afirmamos, são conservadoras.

Todavia, é de grande relevância cogitarmos sobre a qual paradigma epistemológico se filiam, possivelmente, esses dois pesquisadores e essa pesquisadora para que possam forjar tal posicionamento via linguagem, para que, assim, possamos ampliar a compreensão acerca do que denominamos de "linguagem não-binária" e possamos pensar acerca de suas demandas e implicações políticas, bem como sobre possibilidades e estratégias de usos dessa linguagem no universo acadêmico. 


\section{Fazer ciência: abordagem indisciplinar e paradigma epistemológico interpretativista}

De modo geral, quando pensamos sobre o "fazer científico" ainda é a compreensão de que a "ciência" está para o domínio da objetividade e da neutralidade científica, sentidos que se pautam na percepção de um "raciocínio lógico", de causalidade entre os fenômenos estudados, esperando um distanciamento de quem pesquisa, isto é, um certo afastamento do objeto estudado, para não "interferir" em sua "essência", processo que garantiria a "neutralidade científica", tal como problematizada por Moita Lopes (2004; 2013) e Bortoni-Ricardo (2008). Para esse e essa linguista, o fazer científico, nesses moldes, está para o paradigma epistemológico cartesiano-positivista, que parece ainda se pautar no empirismo do século XVII, pautado na "comprovação".

Logo, conforme discute e problematiza Perrotta (2004), nesses parâmetros, é recomendada uma escrita acadêmica da qual se espera a "impessoalidade" e a objetividade, aspectos compreendidos como constituintes da denominada "linguagem científica", entendida como uma "prática legitimada". Para essa pesquisadora, para essa linguagem legitimada está a impessoalidade, que

(...) pode ser conseguida com o uso da voz passiva - foi observado, foi realizado - ou da terceira pessoa do singular com o pronome se [compreende-se, objetiva-se, afirma-se], ou de expressões tais como o presente estudo/trabalho, a presente pesquisa/dissertação" [inserção nossa] (PERROTTA, 2004, p. 25).

Segundo reflete Perrotta (2004), ainda nessa orientação pode aparecer, quando muito, a primeira pessoa do plural, "nós" - "destacamos", "compreendemos" e "objetivamos", mas nunca os usos de "destaco", "compreendo" e "objetivo", na primeira pessoa do singular, "eu", para, desse modo, produzir efeitos de distanciamento, pois, na perspectiva da ciência modernista é condenada/proibida a marcação da subjetividade. Todavia, Perrotta (2004), sob uma perspectiva enunciativo-discursiva, alerta-nos para o fato de que ao usarmos a palavra ela já está impregnada da nossa expressividade. Logo, para ela, "a própria pretensão de transmitir impessoalidade já torna o uso da voz passiva expressivo, não-neutro, pois afirma um juízo de valor do autor-cientista, o que pensa deva ser um trabalho acadêmico" (PERROTTA, 2004, p. 25).

Noutra compreensão do fazer científico, a exemplo das ideias de Moita Lopes (2013), quando consideramos o mundo em que vivemos, de desenraizamentos e, portanto, de incertezas cotidianas, e quando consideramos como as coisas estão se desenvolvendo, pensar ciência apenas pelo paradigma cartesiano-positivista configura-se como um baixo nível de compreensão/reflexão epistemológica e falta de compreensão da pesquisa contemporânea. Para Moita Lopes (1994; 2004; 2013), faz-se de fundamental importância uma abordagem interpretativista, aquela que não se interessa apenas pelos números, pela quantidade, pela generalização - pela neutralidade e objetividade - mas por fatos qualitativos particulares, focalizando, assim, os aspectos processuais e nesses a pluralidade de vozes em ação no mundo social, considerando, portanto, questões de poder, de história, de ideologia e de subjetividades, pois entende que aí estão os significados, que constroem, destroem e 


\section{REVISTA DA ABRALIN}

reconstroem o mundo. Nessa perspectiva epistemológica, é imprescindível nos questionarmos "quais valores são preferenciais?", de modo a assumirmos uma posição política clara. Essa postura deve estar também na escrita acadêmica.

Nessa abordagem interpretativista, em postura epistemologia queer, devemos "interrogar a emergência e o desaparecimento do humano nos limites do que podemos saber [para assim] revigorar os projetos intelectuais da crítica, do questionamento (...)" [inserção nossa] (BUTLER, 2011, p. 31). Falamos, então, em ética, em responsabilidade com as outras pessoas na produção e na escrita do saber científico. Podemos falar, então, de uma "ética bixa" (VIDART, 2019), uma "ética transviada", conforme Santos Filho (2020), a partir da qual na produção dos saberes se evita estar a serviço de uma ética colonizadora, de uma ética neoliberal, focalizando, então, na recuperação da solidariedade entre os sujeitos oprimidos, discriminados e perseguidos.

Nesse sentido, a produção de saber, conforme Moita Lopes (2013), precisa ser deslocada da relação "Estado nacional" e "língua nacional", frutos de modelos europeus, frutos da modernidade, que se pautam na essência e na pureza dos sujeitos e da língua. O saber, então, precisa ser desterritorializado, já que o mundo é constituído por fronteiras porosas. Para esse linguista, devemos pensar diferente e nos movermos em outra lógica. Ou seja, para ele, devemos pensar o que não deveria ser pensado, fazer o que não deveria ser feito, tematizar o que não deveria ser tematizado, isto é, trabalhar com tópicos inimagináveis, transgressores, indisciplinares, quebrando a unicidade.

Para Moita Lopes (2013), só assim produzimos inovação, que é crucial em pesquisa, e ousadia. Nessa dimensão, o fazer científico busca não um distanciamento, mas uma "proximidade crítica", conforme Boaventura Souza Santos, citado por Moita Lopes (2013), apostando no "conhecimento interessado", apostando, então, em discursos que possam reinventar a vida social, tal como propõe Judith Butler, citada por Moita Lopes (2013). Nessa direção, ainda conforme Moita Lopes (2013), afastamo-nos da concepção de língua pura, neutra, autônoma, transparente e representacional, noções pautadas na ideia de essência e de pureza, noções que estão para as "normas" e que mantêm, em diversos aspectos, desigualdades sociais, de classe, de raça, de gênero e de sexualidade, e que são responsáveis por sofrimentos. Assim, "é tempo de repensarmos os percursos epistemológicos que têm nos orientado" (MOITA LOPES, 2004, p. 161), pois "é tempo de dialogar com esse novo mundo" (MOITA LOPES, 2004, p. 163). É tempo também de repensar sobre a orientação para a escrita acadêmica, tal como a que pede impessoalidade e neutralidade, e, assim, irmos na direção de uma "escrita interessada".

No que se refere à língua(gem), Melo (2021) apresenta uma noção que tem forte relação com as reflexões de Moita Lopes $(1994 ; 2004 ; 2013)$, tornando-se importante aqui para pensarmos sobre a produção de conhecimento. Para esse analista crítico do discurso, devemos compreender que

A linguagem não é um atributo da vida que a gente usa, coloca em nós - um instrumento para a interação social (...) do qual a gente pode se apartar (...) [que] eu coloco em mim, coloco e tiro. A linguagem (...) é o que nos constitui como seres humanos: a gente se constitui como sujeito pela linguagem o tempo inteiro. A linguagem é um trabalho que se confunde com a própria humanidade. Ser humano é um exercício de linguagem o tempo inteiro, porque é por meio dela que a gente significa as coisas no mundo, dá significado a nós mesmos (...). Em relação a gênero, a gente está o tempo inteiro se 


\section{REVISTA DA ABRALIN}

generificando e generificando as outras pessoas pela linguagem. A gente está o tempo inteiro classificando as pessoas pela linguagem. (MELO, 2021)

Ao consideramos todos esses aspectos acerca da produção do saber científico, e também acerca da língua(gem), filiando-nos ao paradigma epistemológico interpretativista, em diálogos com um paradigma epistemológico queer, buscamos uma "proximidade crítica", para a produção de um "conhecimento interessado". Logo, compreendemos que, conforme Hooks (1994), citado por Moita Lopes (2004, p. 166), "'não há mais espaço para uma racionalidade descorporificada"'.

Desse modo, pensar, problematizar e usar uma "linguagem inclusiva", tal como a "linguagem não-binária", é de extrema relevância, inclusive na esfera acadêmica, afrontando o ideal linguístico e o ideal de gênero social e colocando em pauta também pela escrita transgressiva e disruptiva a generificação dos sujeitos em nossos usos de linguagem, já que fomos levades a todo tempo a usar classificações de pessoas através de palavras/expressões como "o outro", "aqueles" etc., através do "masculino genérico", conforme argumenta Melo (2021), apagando o feminino e todas as demais expressões e vivências de gênero, incluindo aí les não-bináries. Mas, o que é uma linguagem não-binária? Quais suas implicações políticas? Quais suas possibilidades de uso na escrita acadêmica?

\section{Linguagem não-binária, linguagem inclusiva, em alguns usos acadêmicos}

Para pensarmos sobre o que é linguagem não-binária, devemos voltar ipsis verbis (por isso aspeada) à conceituação apresentada no início deste texto. Assim, feitos os diálogos com a, [1] es e os linguista(s) Bagno (2019), Borba e Medeiros (2021), Borba (2020), Carvalho (2021), Lagares (2018; 2020), Lau (2019a; 2019b), Santos Filho (2015; 2017) e Silva (2018), tal como já dissemos, a "linguagem nãobinária' diz respeito aos (usos de) recursos linguísticos que intentam uma marcação linguística nãobinária de gênero (social), ao subverter a binariedade de gênero linguístico (masculino e feminino), podendo inclusive subverter os recursos (clássicos) morfológicos de gênero, para alcançar tal efeito".

Todavia, essa conceituação carece de mais aprofundamento, de modo a darmos conta de diversos aspectos que estão envolvidos no que podemos denominar de linguagem não-binária, que, a princípio, já compreendemos ser uma "linguagem inclusiva", justamente devido a sua demanda social e ao seu caráter político-ideológico, que visa incluir. Nesse sentido, para falarmos de linguagem nãobinária, devemos entender que sua conceituação envolve diversos aspectos,

a) Compreender a dimensão técnica, linguístico-formal, e sua implicação frente à "norma(tividade/lidade)" linguística;

b) Saber acerca da demanda, por pessoas trans não-binárias; 


\section{REVISTA DA ABRALIN}

c) Saber dos objetivos;

d) Saber o histórico; e

e) Compreender seu caráter de ativismo linguístico e as implicações políticas, que perpassam por críticas e oposição recebidas; e, por fim,

f) Compreender as possibilidades de uso, que é o caráter que mais de perto nos interessa nesse momento, frente à demanda da escrita acadêmica, junto ao item a).

Enfrentando tais aspectos, entendemos com Lau (2019b) que a linguagem não-binária é uma nova forma de linguagem aplicada na língua portuguesa, uma linguagem que marca o gênero de modo não-binário. Para esse linguista, a linguagem não-binária foge da norma (padrão e culta), pois foge do "masculino genérico" e do "binarismo de gênero", buscando uma transformação nos usos linguísticos que se constitua em uma "transformação". Nesse sentido, tais usos estão para uma forma-ação (linguística) trans. Mas, o que é marcação de gênero? Para Lau (2019b) e Melo (2021), a marcação de gênero é uma categoria nominal (gramatical) no sistema linguístico em Língua Portuguesa, que é binária, isto é, que marca as palavras como masculinas ou femininas, inclusive as palavras referentes a seres inanimados. Tal característica linguística é um traço da língua portuguesa, mas não só (CARVALHO, 2021; MELO, 2021). Assim, temos - aqui apresentados de modo bem simples - usos $^{5}$ como os que seguem, em Língua Portuguesa:

a) o carr-o, a pont-e, a carroç- $a$ [palavras referentes a seres inanimados em que não há marcação de gênero; nessas palavras a marcação não é no nome, é no determinante, nesses casos um artigo definido, masculino ou feminino; nesses casos, as vogais finais não marcam gênero, são vogais temáticas, pois apenas completam o tema da palavra, marcando-as como nomes];

b) o/a lingu-ista; o/a estud-ante [palavras referentes a seres humanos e que, do mesmo modo, não há marcação de gênero [masculino ou feminino] no nome, mas no determinante; nesses casos, o morfema final é indicador de agente; são palavras denominadas de "substantivos de dois gêneros, sem flexão" (BATISTA, 2011)];

c) a criança, a pessoa, o indivíduo, o sujeito [nesses casos, não há marcação de gênero na palavra, apenas a marcação de um único gênero através do determinante; no entanto,

\footnotetext{
${ }^{5}$ Os exemplos mencionados estão para uma abordagem formal da língua, de caráter prescritivo, ou mesmo descritivo, que ganha socialmente (e academicamente) teor de ideial linguístico; estão para uma abordagem tradicional. A discussão neste artigo expande essa perspectiva.
} 


\section{REVISTA DA ABRALIN}

socialmente, mesmo com a marcação de um gênero no determinante, são usadas para referenciar qualquer gênero, ou considerada sem gênero; tradicionalmente, são palavras denominadas de "substantivos de gênero único" (BATISTA, 2011)];

d) o menin-o, a menin-a [nesses casos, a marcação de gênero [masculino ou feminino] é feita na própria palavra, através de morfemas gramaticais de gênero, quais sejam "-o" e "-a", como vemos; além disso, há marcação no determinante, ou masculino ou feminino, em concordância; são palavras denominadas de "substantivos de dois gêneros, com flexão" (BATISTA, 2011)];

e) o colaborador[ø], a colaboradora; o bacharel[ø], a bacharela [nesses casos, o masculino é pressuposto a partir da ausência de um marcador de gênero, é o morfema zero [ø], quando em processo de comutação, e o feminino é marcado pelo morfema "-a", tradicional; há marcação de gênero também no determinante];

f) o homem, a mulher; o pai, a mãe [nesses casos, o gênero [masculino ou feminino] é marcado na própria forma lexical, sendo uma forma para cada gênero, formando um par; a marcação também ocorre pelo determinante].

Nesses casos, vemos claramente que a categoria nominal de gênero se constitui como binária, por configurar as palavras em dois polos: "masculino" e "feminino". Conforme abordagens gramaticais normativas e abordagens descritivas da língua, tal como discutidas e problematizadas em Batista (2011), Carvalho (2021), Lagares (2018) e Silva (2018), por exemplo, essa categoria de gênero serviria apenas para dividir nomes (e pronomes) em dois grandes grupos e estabelecer relações de concordância. Por essa compreensão, o sistema de gênero binário seria apenas um conjunto de relações de unidades formais que formariam um sistema, não tendo conteúdo lexical (LAGARES, 2018), isto é, não se referiria aos gêneros sociais, que são os modos, de expressão e de vivência, de como as pessoas se reconhecem, que ultrapassam a binariedade, podendo estar num espectro que, para além dos dois polos, há diversos outros modos, tais como pessoas trans, homens trans, mulheres trans, trans não-binaries, agênero etc. Nessa discussão, Batista (2011) explica que linguistas (Que linguistas!?) consideram equivocadas a relação feita entre gênero gramatical com gênero social. Logo, nesse sentido, não seria possível, tampouco válida, uma reivindicação pela não binariedade no sistema linguístico de gênero, para dar conta da dinâmica de gêneros sociais, incluindo todas as dissidências frente ao sistema de reconhecimento de gênero em nossas sociedades ocidentais.

Porém, Lagares $(2018 ; 2020)$ afirma que o morfema gramatical de gênero é um morfema ambíguo, tendo sempre [além de conteúdo gramatical - aquele para estabelecer relações de concordância] conteúdo lexical, isto é, sentido de gênero social, ao se referir a seres animados. Acrescento que para seres animados não-humanos faz referência ao sexo. Ou seja, para esse linguista, em "o menino", o artigo definido masculino e o morfema gramatical de gênero estão para significados de "varão", de "macho", e que no sintagma "a menin-a", o artigo definido está para "mulher", "fêmea", assim como o morfema gramatical de gênero. Para Lagares $(2018 ; 2020)$, na prática social há sim ambiguidade na 


\section{REVISTA DA ABRALIN}

semântica do sistema de gênero, mas que não é tão clara assim. Há ainda a ideia de que o gênero masculino seria o "genérico", o "geral", não sendo marcado gênero, portanto. Entretanto, diversos estudos nos apontam que o morfema gramatical de gênero masculino é lido pela semântica de "masculino", não de geral.

A esse respeito, para Carvalho (2021, p. 10-11), o que há nesse traço nominal de gênero é uma padronização "a partir da metáfora do espelho, cuja imagem projetada é a luz refletida por um corpo em sua superfície". Aqui, ao falar de superfície do corpo está mencionando as genitálias, o sexo. Para ele, "o que se consagrou como marcas de gênero gramatical nas línguas indo-europeias foi o reflexo dos corpos cujas vozes eram audíveis, ou quase (em se tratando do feminino), enquanto os novos corpos contemporâneos não cabem mais no espelho ocidentalizado materializado na gramática de gênero" (CARVALHO, 2021, p. 11). Quais vozes foram/são audíveis? Com certeza as do homem, branco, cis(hétero), cristão e economicamente favorecido; a voz do "patrão". Nessa perspectiva, para Carvalho (2021, p. 09), a categoria nominal de gênero deve ser questionada por não cumprir seu papel cognitivo e por não capturar seus potenciais referentes no mundo contemporâneo, a fluidez de corpos, de gêneros. Nessas considerações, o sistema linguístico é compreendido como um "cistema", conforme Lau (2019a; 2019b), um sistema linguístico cisgênero, cis(hetero)normativo, no qual "cis-" está para fazer referenciação às pessoas que se identificam com o gênero imposto no nascimento, por condição da genitália, não abarcando, portanto, as "pessoas T", aquelas que transgridem essa ordem de gênero, transgêneros, transexuais, travestis e, em especial, às não-binárias. Restringe-se ao binarismo de gênero.

A partir de uma discussão de Guilherme Ribeiro Colaço Mader, sobre sexismo e políticas linguísticas de gênero, Borba (2020) argumenta que a explicação de gênero, na gramática latina, era a de que o masculino era o "gênero mais nobre", inclusive o "masculino gramatical". Logo, o que se tinha era uma explicação de cunho sexista, vinculada essencialmente à questão social, mas que, no século XX, pelas lentas da ciência, esse caráter ganhou uma "roupagem científica", passando a ser nomeado como gênero não-marcado, ocultando, portanto, essa semântica lexical, que foi/é uma "semântica interessada". Essa leitura histórica corrobora a ideia de Carvalho (2021). Assim, passamos a compreender que a norma linguística de gênero é sustentada por um raciocínio (socio)linguístico conservador, seja no arcabouço da gramática normativa, seja no arcabouço (socio)linguístico. Considerando as argumentações aqui realizadas, podemos compreender que tais "normas" estão para o "padrão" e para "gente culta", pautadas em preceitos puristas. Dessa maneira, a partir de Faraco (2008), citado por Bagno (2019), podemos compreender que essa é uma "norma curta", de caráter curto nas explicações, aquela que só se justificava por um preceito conservador, sendo a face visível da "norma oculta", como bem discutiram Borba (2020) e Carvalho (2021).

É dessa compreensão e partindo de suas vivencias que pessoas não-binárias, tal como argumentam Borba (2020) e Melo (2021), lutam por inclusão na linguagem, enfrentando o sistema linguístico e sua norma de gênero. Para Borba (2020), essas pessoas sentem que há, através das práticas linguísticas, manutenção de estruturas de exclusão e de opressão. E há. Mas, muito mais do que focarmos a discussão na dimensão apenas formal-linguística, ou de mudança ou variação linguística, o importante é 


\section{REVISTA DA ABRALIN}

forcamos na reivindicação e seu questionamento do "cistema". Assim, o movimento transfeminista não-binário ao lutar por uma linguagem não-binária está lutando contra a binariedade de gênero, fundada na ideia de identidade pré-discursiva e na ideia de permanência, a de que nunca se deixa o gênero, tal como explica Borba (2020), a partir de Vergueiro (2019), aspectos que deslegitimam as identidades trans. Para Borba (2020), a cisgeneridade talvez seja a ideia mais naturalizada da sociedade. Para esse pesquisador, o questionamento principal é sobre a essencialização identitária de modo binário (BORBA, 2020). Para ele, esse debate atual é tributário de uma longa história do ativismo linguístico feminista, já com mais de 40 anos, desde os anos 1970, que enfrenta(va) o "masculino genérico". Conforme declara Medeiros, em Borba e Medeiros (2021), "para as pessoas não-binárias, não é só colocar um pronome [um nome, um morfema], é viver uma ruptura" [inserção e itálicos nossos], em construções como "elu é linde" e "as pessoas gostam de comer frutas".

Nesse histórico de lutas, o movimento feminista lutou/luta contra o "masculino genérico", de modo a marcar e dar visibilidade às mulheres nas práticas linguísticas, surgindo usos como os de $i$ ) "formas disjuntivas" [formas coordenadas], como "elas e eles", "o professor e a professora", de ii) "feminino genérico", "alunas" (CALDAS-COULTHARD, 2007), de iii) "novas tipografias", como em "alunx", "alun@” ou "alun_", ou de iv) "formas hiperônimas", como em "pessoas", "indivíduos", conforme explica Borba (2020). Para esse linguista, o movimento transfeminista não-binário enfrenta o binarismo de gênero, surgindo daí propostas interventivas como i) "novas tipografias" como marcadores de gênero não-binário, ou neutro, como "-@”, “-x" e “_" (underline), ii) uso da "vogal -e" como marcador de gênero não-binário, ou neutro, como em "alun-e-s", e os iii) "sistemas pronominais" "ile" e "elu". Então, essas são formas mais disruptivas. No que toca aos usos de tipografias, é importante considerar que são notações que não fazem parte da nossa língua, inclusive, não tendo pauta sonora, como argumenta Melo (2021). Mas, há também o v) uso de "formas hiperônimas", em uso de palavras como "pessoa" e "sujeito", por exemplo. É importante considerar que no que se refere a essas propostas interventivas, conforme afirma Melo (2021), "a linguagem não-binária não está para objetos, mas em referência a pessoas". Brune Medeiros, em Borba e Medeiros (2021) chama a atenção para o uso de marcação não-binária na palavra "corpo", como em "corpes trans", como exemplifica, ou em "corpes escondides", num título de capítulo de Andrógina (2021), incluindo, inclusive, concordância nominal de gênero. Veja no excerto abaixo, de Andrógina (2021), em "Escrevi um livro errado", uma espécie de livro-intervenção, o uso da flexão não-binária na palavra "corpo". Uma boa explicação para essa flexão não-binária de gênero para a palavra "corpo" é o fato de que o corpo é o lugar em que se produz o gênero.

\section{Excerto 04}

(...) nós ('corpxs' e corpes, que se deslocam das políticas de alteridade ou da universalidade masculina), somos imperceptíveis na estabilidade das dinâmicas sociais ([mas] nossa existência é tão importante quanto a de qualquer outra identidade (...) (inserção nossa) (ANDRÓGINA, 2021, p. 33) 


\section{REVISTA DA ABRALIN}

Quais as possibilidades de uso, então, da linguagem não-binária? A Associação Nacional de Travestis e Transexuais (ANTRA) apresentou recentemente algumas sugestões para falar/escrever com marcação não-binária ou de neutralidade de gênero, que são aqui mencionadas, com alguma intervenção. A recomendação é a de:

a) evitar uso de artigos e pronomes com marcação de gênero binário para substantivos uniformes, aqueles substantivos de dois gêneros, sem flexão [Colegas ajudaram João a escrever o texto];

b) não realizar contração da preposição "de" com artigos/pronomes, pois marcam gênero [Algumas tarefas são de responsabilidade de estudantes];

c) substituir nomes marcados por gênero [com caráter indefinido] por substantivos de gênero único, que assumem a forma de palavra hiperônimas [As pessoas que leem o texto se sentem incluídas com o uso de uma linguagem neutra] [O leitor se sente incluído com o uso de uma linguagem neutra];

d) substituir sujeitos de sentenças [marcados por gênero] pela expressão "pessoa que + ação" [Pessoas que cozinha desenvolvem muito o olfato] [Os cozinheiros desenvolvem muito o olfato];

e) usar nome de agrupamento no lugar de sujeitos no plural [marcados por gênero] [O corpo discente organizou um ciclo de palestras na Universidade] [Os alunos organizaram um ciclo de palestras na Universidade];

f) substituir nos "nomes de dois gêneros, com flexão", os morfemas binários por alguma forma disruptiva, inclusive na concordância com artigos [ Xs meninxs jogam bola; Es menines jogam bola];

g) usar os sistemas pronominas "ile" e "elu";

h) não usar a palavra "homem" como "sinônimo de ser humano".

A respeito de usos da linguagem não-binária, Hélito Lau (2016), em sua dissertação, defendida no "Programa de Pós-Graduação em Linguagem, Identidade e Subjetividade", da Universidade Estadual de Ponta Grossa, no Paraná, utilizou-se de recursos disruptivos da linguagem não-binária para marcar sujeitos não-binários, a exemplo de:

a) pronome "elu", para fazer referenciação a não-bináries; 


\section{REVISTA DA ABRALIN}

b) vogal "-e" no paradigma morfológico, substituindo os morfemas tradicionais "-a" e "-o", em nomes, substantivos e adjetivos (de dois gêneros com flexão), bem como em determinantes ("outres");

c) no caso de nomes de dois gêneros, com flexão, mas com masculino zero, no plural, "professores", inseriu a vogal "i", na construção do marcador de plural, e gênero, "-ies";

d) pronomes definidos (o, a, os, as) substituídos por "le" e "les", respectivamente singular e plural;

e) pronomes indefinidos (um, uma, uns, umas) são substituídos por "ume" e "umes".

Na mesma linha de produção escrita, Andrógina (2021), em seu livro "intervenção", traz o uso do "-x" (e também do "-e"), recurso disruptivo da linguagem não-binária, para marcar não-bináries, tal como podemos ver nos trechos destacados:

\section{Excerto 05}

A intenção com a Plataforma de Pesquisa e Arte a Andrógina (2016) é gerar autonomia de fala e ação, em que x artista não é apenas uma voz, mas a análise crítica sobre aspectos culturais e sociais em torno de gênero e sexualidade (...) (ANDRÓGINA, 2021, p. 7)

(...) nós ('corpxs' e corpes, que se deslocam das políticas de alteridade ou da universalidade masculina), somos imperceptíveis na estabilidade das dinâmicas sociais ([mas] nossa existência é tão importante quanto a de qualquer outra identidade (...) (inserção nossa) (ANDRÓGINA, 2021, p. 33)

A ideia da presença de outras identidades, afetam a realidade a qual estamos inseridxs. (ANDRÓGINA, 2021, p. 17)

(...) o fato de não ter uma obrigação aparentemente ou incumbida a nós a priori, ou por um modelo social pré-determinado, ainda é um processo em andamento ao qual não há escapatória e obviamente será o melhor para todxs (...) (ANDRÓGINA, 2021, p. 23).

Após essas informações, uma última observação acerca desse aspecto técnico (formal-linguístico) da linguagem não-binária é a de que esses recursos que dão o caráter de gênero não-binário na linguagem podem também gerar a ideia de gênero neutro, se o uso for específico para pessoas nãobinárias, no primeiro caso, e se o uso for para não marcar gênero, no segundo caso. Por exemplo, ao usar o "-x", Andrógina (2021) dá ao uso um caráter não-binário. Entretanto, quando esse mesmo recurso foi usado por Lagares (2018), seu uso tem caráter de neutralidade de gênero. Para Melo (2021), mesmo que tais recursos linguísticos disruptivos causem estranhamentos, seus usos são relevantes. Esse linguista ainda argumenta que "falar de linguagem não-binária é falar de uma atitude política, 


\section{REVISTA DA ABRALIN}

muito mais do que falar de mudança linguística" (MELO, 2021). Mas, é certo que as reações conservadoras ocorrem, ou melhor, têm ocorrido, sejam em perspectiva normativa, não aceitando tais usos, sejam em perspectiva apocalíptica, no sentido de dizer que tais usos se configuram como o fim dos tempos, conforme explica Borba (2020), que argumenta que tais críticas e reações aos usos da linguagem não-binária se configuram como prótese para a defesa da cisgeneridade e de um ideal específico de nação. Ou seja, para ele, os haters da linguagem não-binária usam uma ideia de língua para defender um ideal de sociedade.

\section{Considerações}

Feita a discussão em defesa de um fazer científico interessado e de uma escrita acadêmica interessada, no sentido de ter agência, de ter apresentado uma noção de linguagem não-binária, em que são problematizados seus aspectos linguístico-formais, e mesmo entendendo que é possível/viável o uso de tal linguagem na esfera acadêmica, em artigos, capítulos de livros, livros e em dissertação, a questão "E a norma culta?", em seu ideal normativo linguístico de gênero, permanecesse nos assombrando. Seguindo a radicalização de Bagno (2019), ao argumentar que a norma culta é uma forma elitista e conservadora de ver a língua, sigo-a e sustento: "A norma culta [de gênero] que se lasque, que se dane, que se esboroe", porque "toda e qualquer maneira de falar vale ouro na luta contra o fascismo" (BAGNO, 2019, p. 16). É nessa direção de afrontamento que dissemos o que significa, quais os aspectos e quais as possibilidades de uso da linguagem não-binária, situando-a no cenário da escrita acadêmica, como uma escrita imbuída de agência, em filiação a um paradigma epistemológico interpretativista-queer.

Entretanto, devido ao fato de essa discussão ter sido pela demanda de uma pessoa que tem interesse em escrever seu trabalho de conclusão de curso usando recursos da linguagem não-binária, para pensar mais a respeito, deixo a orientação de Perrotta (2004), quando diz que o quanto se deve ou não seguir práticas legitimadas ou o quanto se deve ou não propor novas maneiras de tratar o tema da pesquisa, incluindo aí questões sobre a linguagem, deve ser acertado com o orientador, a orientadora ou o orientadorie. Faço minhas as palavras dela. Todavia, não podemos esquecer que o universo acadêmico é necessariamente um espaço político, um espaço de poder. Logo, usar a linguagem não-binária na escrita acadêmica é atuar para provocar certos/urgentes deslocamentos de sentido, atuando na microfísica das tramas de forças do dizer científico, de modo a gerar reconhecimento a todes.

\section{REFERÊNCIAS}

ANDRÓGINA. Escrevi um livro errado. São Paulo, 2021. Disponível em < $\underline{\text { https: } / / 2 e 6 f a 6 f 7-404 a-44 a 3-}$ 


\section{REVISTA DA ABRALIN}

847edccb868a6cc1.filesusr.com/ugd/ccfd2f_c720f9940da1460d986e9bf4a74b1393.pdf >. Acesso em 30 de setembro de 2021

BAGNO, Marcos. A norma culta que se lasque! In. Marcos Bagno. Objeto língua. São Paulo: Parábola Editorial, 2019, p. 13-16.

BATISTA, Ronaldo de Oliveira. A palavra e a sentença - estudo introdutório. São Paulo: Parábola Editorial, 2011.

BAZERMAN, Charles. Gênero, agência e escrita. São Paulo: Cortez, 2006.

BORBA, Rodrigo. Linguagem neutra. ALAB - Associação de Linguística Aplicada do Brasil, 2020. Disponível em < https://www.youtube.com/watch?v=BQ_PGwHFvLg >. Acesso em 30 de setembro de 2021.

BORBA, Rodrigo; LOPES, Adriana Carvalho. Escrituras de gênero e políticas de différance: imundície verbal e letramentos de intervenção no cotidiano. Linguagem e Ensino, vol. 21, p. 241-285, 2018.

BORBA, Rodrigo; MEDEIROS, Brune. Linguagem neutra. EP \#58. 2021. Disponível em < https://larvasincendiadas.com/2021/04/15/58-brune-medeiros-rodrigo-borba-linguagem-neutra/ >. Acesso em 30 de setembro de 2021.

BORTONI-RICARDO, Stella Maris. O professor pesquisador - introdução à pesquisa qualitativa. São Paulo: Parábola Editorial, 2008.

BUTLER, Judith. Vida precária. Contemporânea - revista de Sociologia da UFSCar, nº 1, 2011.

CALDAS-COULTHARD, Carmem Rosa. Caro colega: exclusão linguística e invisibilidade. Discurso e Sociedad, vol. 1(2), p. 230-246, 2007.

CARVALHO, Danniel da Silva. A domesticação da gramática de gênero. Campinas, SP: Pontes Editores, 2021.

FABIANO, Sulemi. Escrita acadêmica: a arte de dialogar com a palavra do outro. UERN Oficial, 2020. Disponível em < https: //www.youtube.com/watch?v=BSKmf1Xfcfg $>$. Acesso em 30 de setembro de 2021.

FABIANO, Sulemi. Pesquisa na graduação - a escrita do gênero acadêmico. Cáceres: Unemat Ed., 2004.

LAGARES, Xoán Carlos. Política linguística - desafios glotopolíticos (minicurso - aula 5). Parábola Editorial, 2020. Disponível em < https://www.youtube.com/watch?v=mNI2SEsKO2k >. Acesso em 30 de setembro de 2021.

LAGARES, Xoán Carlos. Qual política linguística? Desafios glotopolíticos contemporâneos. São Paulo: Parábola Editorial, 2018.

LAU, Héliton Diego. Pelo direito e orgulho de ser heterossexual no terceiro domingo de dezembro: os discursos de Carlos Apolinário e Eduardo Cunha nos PLs 294/2005 e 1672/2011. Dissertação. Mestrado em Linguagem, identidade e subjetividade. Universidade Estadual de Ponta Grossa, 2016.

LAU, Héliton Diego. Pensando fora do cistema: uma reflexão sobre a linguagem não-binária. Uniletras, Ponta Grossa, v. 41, n. 2, p. 262-282, jul/dez. 2019b.

LAU, Héliton Diego. Propaganda inclusiva e uma conversa sobre representatividade na língua portuguesa: notas sobre a linguagem não binária. In. Héliton Diego Lau, Zuleica Aparecida Michalkiewicz. Pesquisar em tempos de resistência: a balbúrdia de quem faz Linguística Aplicada. São Paulo: Pimenta Cultural, 2019c, p. 185-220. 


\section{REVISTA DA ABRALIN}

LEWIS, Elizabeth; BORBA, Rodrigo; FABRÍCIO, Branca Falabella; PINTO, Diana de Souza. Introdução: Cu-irizando desde o Sul. In. Elizabeth Lewis, Rodrigo Borba, branca Falabella Fabrício e Diana de Souza Pinto (Org.). Queering paradigms IVa - Insurgências queer ao Sul do Equador. New York: Peter Lang, 2017. p. 1-12.

LOPES, Adriana Carvalho. Aula aberta: Linguagem neutra: relações de gênero na Língua Portuguesa. LEGESEX UFRRJ, 2021. Disponível em < https://www.youtube.com/watch?v=nWR_VXSwnY4 >. Acesso em 30 de setembro de 2021.

MELO, Iran. Linguagem não-binária. Canal Perturbação, 2021. Disponível em <

https://www.youtube.com/watch?v=qh3GqhL-V40 >. Acesso em 30 de setembro de 2021.

MOITA LOPES, Luiz Paulo da. Contemporaneidade e construção de conhecimento na área de estudos linguísticos. SCRIPTA, v. 7, n. 14, p. 159-171, 2004.

MOITA LOPES, Luiz Paulo da. Pesquisa em Linguística Aplicada: entre lugares/margens, discursos emergentes e política. Conversas - Questões de Linguagem. 2013. Disponível em <

https://www.youtube.com/watch?v=bWFAkLwTMM8\&t=16s > . Acesso em 27 de setembro de 2021.

MOITA LOPES, Luiz Paulo da. Pesquisa interpretativista em linguística aplicada: a linguagem como condição e solução. DELTA, vol. 10, nº 2, 329-338, 1994.

PELÚCIO, Larissa. O Cu (de) Preciado - estratégias cucarachas para não higienizar o queer no Brasil. Printemps, n 9, p. 123-136, 2016.

PERROTTA, Claudia. Um texto para chamar de seu - preliminares sobre a produção do texto acadêmico. São Paulo: Martins Fontes, 2004.

SANTOS FILHO, Ismar Inácio dos. Linguística Queer: na luta discursiva, como/sobre prática de ressignificação. In. Danilo da Conceição Pereira Silva, Iran Ferreira de Melo e Lorena Gomes Freitas de Castro. Dissidências sexuais e de gênero nos estudos do discurso. Aracaju: Criação Editora, 2017, p. 153-184.

SANTOS FILHO, Ismar Inácio dos. Por lentes queer: linguagem, gênero, sexo e sexualidade. In. Questões de gênero e sexualidade na Linguística Aplicada. ALAB - Associação de Linguística Aplicada do Brasil, 2020. Disponível em < https://www.youtube.com/watch?v=ak-98j9bPz8 >. Acesso em 30 de setembro de 2021.

SANTOS FILHO, Ismar Inácio dos. Preâmbulo para uma linguística queer. Seminário de pesquisa: Introdução à linguística queer. Programa de pós-graduação em Letras. Maringá: UEM, 2015. Mimeo.

SILVA, Thainá Fernanda da. A variação morfológica em "todes", "amigues" e "menines" como estratégia performativa identitária insurgente. Monografia (Licenciatura em Letras) - Universidade Federal de Alagoas. Curso de Licenciatura em Letras. Delmiro Gouveia, 2018.

TIBURI, Marcia. Feminismo em comum para todas, todes e todos. Rio de Janeiro: Rosa dos Tempos, 2018.

VIDAR, Paco. Ética bixa - proclamações libertárias para uma militância LBTQ. São Paulo: No 1 Edições, 2011. 